Aging without children

Dr. Katya Ivanova ${ }^{1}$ and Prof. dr. Pearl Dykstra

Erasmus University Rotterdam

${ }^{1}$ Corresponding author. Address: Department of Sociology, Erasmus University Rotterdam, PO

Box 1738, 3000 DR Rotterdam, the Netherlands; e-mail: ivanova@fsw.eur.nl 
This issue of Public Policy and Aging Report brings into focus the fact that the "greying" of Western countries is playing out at the backdrop of fundamental re-thinking and restructuring of the institution of "the” family. These changes are happening at a time when even countries with a long-standing tradition of generous state-funded social support systems are beginning to shift at least some care obligations away from the state in pursuit of a society based on the principle of individual responsibility (e.g., the Netherlands). The implicit assumption underlying this shift is that family members (and adult children in particular) will step in as needs for care and support arise. However, what does this mean for those individuals who, by choice or involuntarily, do not have children in old age (for an overview of routes into childlessness, see Keizer, Dykstra, \& Jansen, 2008; Miettinen, Rotkirch, Szalma, Donno, \& Tanturri, 2015)? Different terms have been used to describe this population (childless, child-free, adults without children, nonparents) and it is important to recognize the potential normative perceptions of family life trajectories which they might convey. Here, we have chosen to use the terms “childless” and "nonparent” entirely in the interest of succinctness.

\section{Trends in childlessness}

Overall, a positive trend in childlessness rates for cohorts born after 1950 can be observed across Western societies. According to data from the OECD (OECD, 2014), whereas some countries are seeing a slight increase in childlessness (from 16.9\% of Dutch women born in 1955 to $18.3 \%$ of women born in 1965), the trend is decidedly more dramatic in others (for Italy from $12.7 \%$ to $24 \%$ of the same cohorts). In the United States, a largely stable or slightly decreasing trend in childlessness is observed (from $16.3 \%$ of women born in 1955 to $14.4 \%$ of women born in 1965). Irrespective of the national context, these statistics mark a remarkable 
increase compared to earlier generations (in the United States, 7.4\% of women born in 1940 were nonparents compared to the $14.4 \%$ for the 1965 cohort).

Getting a firm grip on the size of the permanently childless population is challenging (Dykstra, 2009). Foremost, our understanding of what share of the population does not have children at the end of their reproductive careers (between the ages of 40 and 45 for women), is based primarily on female fertility histories (as birth certificates usually list the name of the mother but not necessarily that of the father). This means that we have not only continued to operate under the assumption that fertility is a "female" life domain, but also, that we might be misrepresenting the proportion of permanently childless men. Another important point to make here is that the statistics of nonparents are based on the proportion of women who did not have any biological (or sometimes, adopted) children. Even when one has taken on a parenting role for the children of a partner, those step relations are not considered in the official statistics (unless, potentially, codified via adoption). For example, based on the 2007/2008 data from the Norwegian Generations and Gender Survey (Vikat et al., 2007), we can see that the percentage of women age 40 or older without biological children is $11.9 \%$ which drops to $9.6 \%$ when we consider non-biologically related children such as stepchildren (authors’ calculation).

Though the previous two remarks suggest that we might be overestimating the number of permanently childless adults, we must also recognize that there is a category of "functionally" childless individuals for whom no official statistics exist. These are individuals who are estranged from their children or who live too far from these potential sources of support. The fact that one has (biological) children does not necessarily signify that these informal sources of support can be accessed when needs arise. Therefore, though the official statistics might imply a levelling off of childlessness for the United States, these numbers do not present an accurate 
picture of the proportion of older individuals who can find themselves without the immediate support of an adult child.

\section{“The” childless? Diversity in strengths and weaknesses}

In the aging literature, the typical starting point is a focus on what the childless lack. Concomitantly, they are routinely positioned as a group at risk, despite repeated evidence showing that childless older adults do not generally perform worse on a wide range of psychological, social, and economic outcomes (Hank \& Wagner, 2013). Furthermore, regardless of how older adults ended up being childless - by choice or circumstance - they exhibit strengths that have been developed over the course of their lives: high levels of self-reliance, independence, and self-sufficiency (Wenger, 2009). Childless older adults, and particularly childless older women, retire with more assets than parents and enjoy income advantages (Plotnick, 2009). Continuous employment accounts for the higher incomes of childless older women, whereas the higher assets are attributable to not having paid the costs of raising children. The advantaged financial position of the childless reduces the likelihood of needing incometested transfers and increases the likelihood of being able to purchase long-term care insurance.

Another tendency in the research literature is to gloss over differences among childless older adults, obscuring the potential for positive outcomes and the vulnerability for negative outcomes. A key conclusion is that it is not childlessness per se that matters, but how older adults ended up without children. The interplay of gender and marital history is particularly important. Generally, never-married childless older women are well integrated socially, whereas nevermarried and previously married childless older men are more likely to be socially isolated (Umberson, Pudrovska, \& Reczek, 2010). The latter also tend to be more prone to exhibit unhealthy behaviors such as smoking and drinking (Kendig, Dykstra, van Gaalen, \& Melkas, 
2007). In other words, though "the” childless display a number of strengths, there is still a group of nonparents who are likely to be particularly vulnerable in older age. Note that causality is always an issue. Presently, there is insufficient understanding of whether childlessness actually leads to a particular outcome or whether people with particular characteristics are more likely to remain single or to remain nonparents in marriage.

\section{Possible sources of support}

The current scientific debate has centered on the role which kin (defined by biological or legal ties) plays in the provision of care and support for aging adults. The prolific literature has examined the flow of intergenerational exchanges between adult children and their parents (Cooney \& Dykstra, 2013; Kalmijn, 2014). However, older adults can turn to different sources of support when in need, including non-kin (neighbors, friends) and professionals. Yet, the primacy of family members (and immediate family members in particular) as “self-evident” sources of support, is strongly reflected in legal provisions across national contexts. We will illustrate this point with a few key examples.

A number of Western countries feature statutory leave entitlements enabling care for a sick family member. The conditions for taking up the leave, its length, and potential financial remuneration vary tremendously across countries; in the United States, under the Family and Medical Leave Act of 1993, medium and large employers provide employees with 12 weeks unpaid leave for a seriously ill spouse or parent (for an international overview, see Moss, 2014). What all countries share, however, is that the person for whom the leave can be taken has to be kin and in almost all contexts, either a parent or a spouse. This means that in countries like the United States no significant other is entitled to a care leave for a nonparent without a partner. This perception of "who acts as a caregiver” is also strongly reflected in a number of US 
initiatives aimed at recognizing and alleviating caregivers' burden. For example, the "Social Security Caregiver Credit Act” which was introduced to the House of Representatives in 2014 suggests that financial remuneration is made available to "individuals... providing care to a dependent relative” (italics added; Congress, 2014).

Likewise, in the absence of an advance directive dictating the wishes of the individual, in certain states (e.g., California, New Jersey, Texas) physicians cannot consult anyone about the care preferences of their incapacitated patients besides people related by blood, adoption or marriage (American Bar Association, 2014). In a similar vein, the American Internal Revenue Service allows taxpayers to claim non-kin as dependent only if they share a residence yearlong (even if the potential dependent satisfies all other conditions and more than half of his/her yearly income is provided by the taxpayer in question; Internal Revenue Service, 2014). No such coresidence requirement exists for potential dependents related by blood or law.

These are only a few examples of the primacy assigned to kinship ties in the health care and long-term support policies. However, scientific research has highlighted the fact that in the absence of kin (or when these significant others are unwilling / unable to help), non-kin relations, such as close friends but also neighbors, can serve as crucial sources of emotional and practical support (Albertini \& Mencarini, 2012). As mentioned before, childless individuals can adapt to being nonparents and invest significantly in strengthening their non-kin networks (Wenger, 2009). Yet, as illustrated above, non-kin relations often lack the legal rights and the appropriate governmental support to advocate successfully for the needs and wishes of the childless.

Despite the lack of legal or financial support, non-kin often step in to help. Yet, it would be unwarranted to assume that the care needs of childless individuals can be met successfully by galvanizing nonfamily-based social networks. People can turn to different sources of assistance 
as they age - kin, non-kin, and professionals - and yet, the roles which these diverse support networks usually fulfill are rather distinct (Litwak \& Szelenyi, 1969). Friends and neighbors tend to provide emotional support and help with certain practical tasks (e.g., performing small repairs around the house). Important to note here, however, is the fact that the friendship networks which nonparents might have, are likely to be highly age-homogeneous. In other words, even when friends are willing to help, their own advancing age might be inhibiting them from doing so. The more durable and intense bonds which (immediate) family members share are more conducive to the provision of the demanding, long-term care that is often needed eventually. Indeed, as health deteriorates and people begin to face physical limitations in carrying out their daily living activities, those without children can experience shortages in instrumental help (e.g., personal care, cleaning, transportation). It is at this point, that aging nonparents have few other options besides turning to professional help (institutional or home-based).

Of the financial costs associated with aging, long-term institutional care is by far the most costly and has the highest potential out-of-pocket expenses (Knickman \& Snell, 2002). Having children has been shown to delay this entry into long-term residential care (Gaugler, Duval, Anderson, \& Kane, 2007), which implies that nonparents might be more prolonged users of this expensive elderly care service. Nevertheless, it is important to note that it is disability and living alone, rather than simply not having children, which are by far the strongest predictors of institutional admission. Across national contexts, a sustained effort has been committed to ensuring that aging adults live independently for as long as possible. Care from family members has been one of the options for delaying the entry into institutional care - an option not necessarily available to the childless. Yet, studies on the use of professional home help have rendered mixed findings when it comes to the differences between parents and nonparents. 
Whereas some report that childless older adults are more likely than parents to rely on professional home care services (Larsson \& Silverstein, 2004), others report no differences (Aykan, 2003), or, interestingly, a higher use of home services among parents (Blomgren, Martikainen, Martelin, \& Koskinen, 2008). The inconsistency in findings might be attributable to variability in forms of home care, such as whether it is publicly provided or privately paid. Another possibility is that insufficient attention has been given to the opposing views on how childlessness and home help might be linked. The more readily cited perspective states that informal support deficits enhance formal service use among older nonparents. On the other hand, however, the childless could be less likely to use formal services because they lack relatives who serve as advocates on their behalf.

\section{Final remarks}

Governments have a vested interest in the effective functioning of "the” family (Goode, 2003) and have thus, implemented laws which define relationship arrangements and family members' obligations towards one another. What we aimed to highlight here is that if the understanding of who should care for an older individual is restricted to kin (and adult children in particular), this negates the experiences of nonparents. These are individuals who, contrary to popular belief, display a great set of strengths but whose social networks might be unable to or are not assisted in providing support when the needs for care become particularly intense.

Positive signs of change can be observed across national contexts. For example, a number of US states include a "close friend" in the list of potential medical proxies in the absence of an advance health care directive (e.g., Colorado, New York, Tennessee). In the Netherlands, as of July 2015, individuals are entitled to a sick leave in order to provide care for a non-relative (yet, the taxation of inheritance left to non-kin has remained the same - substantially higher than 
when inherited by kin). These are important steps in recognizing that the definition of "the" family, as well as, how people construct their life trajectories, have changed dramatically in the past decades. It is crucial to consider to what extent the current legal arrangements are based on a somewhat outdated perception of what "the" family is.

We would like to conclude this contribution with one final remark. Meeting the need for support of aging nonparents will benefit more than just this growing proportion of Western populations. As previously noted, having (step- or biological) children does not automatically signify the presence of a willing / able support system, as the quality of the emotional bond between family members is a substantially more important predictor of the provision of care than the sheer presence of children. In other words, expanding the discussion of potential sources of support beyond "the" family will be advantageous to others besides nonparents. 


\section{References}

Albertini, M., \& Mencarini, L. (2012). Childlessness and support networks in later life: New pressures on familistic welfare states? Journal of Family Issues, 35, 331-357.

American Bar Association. (2014). Default surrogate consent statues. Retrieved April 9, 2015, from http://www.americanbar.org/content/dam/aba/administrative/law_aging/2014_default_surro gate_consent_statutes.authcheckdam.pdf

Aykan, H. (2003). Effect of childlessness on nursing home and home health care use. Journal of Aging \& Social Policy, 15, 33 - 53.

Blomgren, J., Martikainen, P., Martelin, T., \& Koskinen, S. (2008). Determinants of home-based formal help in community-dwelling older people in Finland. European Journal of Ageing, $5,335-347$.

Congress (2014). H.R.5024 - Social Security Caregiver Credit Act of 2014. Retrieved April 28, 2015, from https://www.congress.gov/bill/113th-congress/house-bill/5024

Cooney, T. M., \& Dykstra, P. A. (2013). Theories and their empirical support in the study of intergenerational family relationships in adulthood. In M. A. Fine \& F. D. Fincham (Eds.), Handbook of family theories: A content-based approach (pp. 356-378). New York: Routledge/ Taylor and Francis.

Dykstra, P. (2009). Childless old age. In P. Uhlenberg (Ed.), Handbook of the demography of population aging (pp. 671 - 690). Dordrecht: Springer.

Gaugler, J. E., Duval, S., Anderson, K. A., \& Kane, R. L. (2007). Predicting nursing home admission in the U.S: A meta-analysis. BMC Geriatrics, 7, 13. 
Goode, W. J. (2003). Family changes over the long term: A sociological commentary. Journal of Family History, 28, 15 - 30.

Hank, K., \& Wagner, M. (2013). Parenthood, marital status, and well-being in later life:

Evidence from SHARE. Social Indicators Research, 114, 639 - 653.

Internal Revenue Service. (2014). Publication 501. Retrieved April 9, 2015, from http://www.irs.gov/publications/p501/ar02.html

Kalmijn, M. (2014). Adult intergenerational relationships. In J. Treas, J. Scott, \& M. Richards (Eds.), The Wiley-Blackwell Companion to the Sociology of Families (pp. 385 - 404). Oxford, UK: Wiley-Blackwell.

Keizer, R., Dykstra, P. A., \& Jansen, M. D. (2008). Pathways into childlessness: Evidence of gendered life course dynamics. Journal of Biosocial Science, 40, 863-878.

Kendig, H., Dykstra, P. A., van Gaalen, R. I., \& Melkas, T. (2007). Health of aging parents and childless individuals. Journal of Family Issues, 28, 1457 - 1486.

Knickman, J. R., \& Snell, E. K. (2002). The 2030 problem: Caring for aging Baby Boomers. Health Services Research, 37, 849 - 884.

Larsson, K., \& Silverstein, M. (2004). The effects of marital and parental status on informal support and service utilization: A study of older Swedes living alone. Journal of Aging Studies, 18, $231-244$.

Litwak, E., \& Szelenyi, I. (1969). Primary group structures and their functions: Kin, neighbors, and friends. American Sociological Review, 34, 465 - 481.

Miettinen, A., Rotkirch, A., Szalma, I., Donno, A., \& Tanturri, M. (2015). Increasing childlessness in Europe: Time trends and country differences (Families and Societies 
Working Paper No. 33). Retrieved April 9, 2015 from

http://www.familiesandsocieties.eu/?page_id=131

Moss, P. (2014). International review on leave policies and related research 2014. Retrieved April 9, 2015, from http://www.leavenetwork.org/lp_and_r_reports/review_2014/

OECD. (2014). SF2.5 Childlessness. Retrieved April 6, 2015, from http://www.oecd.org/els/family/database.htm

Plotnick, R. D. (2009). Childlessness and the economic well-being of older Americans. Journal of Gerontology: Social Sciences, 64B, 767 - 776.

Umberson, D., Pudrovska, T., \& Reczek, C. (2010). Parenthood, childlessness, and well-being: A life course perspective. Journal of Marriage and Family, 72, 612 - 629.

Vikat, A., Spéder, Z., Beets, G., Billari, F., Buehler, C., Desesquelles, A., ... Solaz, A. (2007). Generations and gender survey (GGS): Towards a better understanding of relationships and processes in the life course. Demographic Research, 17, 389 - 440.

Wenger, G. C. (2009). Childlessness at the end of life: Evidence from rural Wales. Ageing and Society, 29, 1243 - 1259. 